\title{
LA PROSTITUCIÓN A DEBATE. ENTRE EL DISCURSO MÉDICO-SOCIAL Y EL FEMINISMO (1847-1875)
}

\author{
Prostitution in the Spotlight: Between Socio-Medical Discourse \\ and Feminism (1847-1875) \\ Isabel EsCOBEDo MugueRZA ${ }^{1}$ \\ Universidad de Zaragoza
}

\section{Resumen}

La prostitución ha generado históricamente, y genera, numerosos debates en torno a su forma de organización y regulación. Entre 1847 y 1875, las cosas no sucedieron de diferente manera. El higienismo y el feminismo fueron los dos discursos que configuraron y sostuvieron las distintas alternativas en lo que a organización de la prostitución se refiere. Así, el higienismo dio lugar al sistema reglamentarista, mientras que el feminismo dará lugar al abolicionismo como sistema principal. No obstante, dentro de este abanico, el anarquismo, encabezado por Mujeres Libres, será el único discurso capaz de subvertir la vinculación permanente entre prostitución y enfermedades venéreas.

Palabras clave: prostitución, abolicionismo, reglamentarismo, higienismo, Josephine Butler, sexualidad

\section{Abstract}

Prostitution has generated, for ages, many debates about their organization and regulation. Between 1847 and 1875, things did not happen differently. The hygienism and feminism were the two discourses that shaped and sustained the different alternatives around organizing prostitution is concerned. Thus, the hygienism led to regulationist system while feminism will lead to abolitionism. However, anarchism,

1 Licenciada en Historia y titulada en el Máster Interuniversitario en Historia Contemporánea. Contratada Predoctoral del Gobierno de Aragón. Correo electrónico: iescobedo@unizar.es. Fecha de recepción del artículo: 12 de noviembre de 2017. Fecha de aceptación: 1 de febrero de 2018. 
led by Mujeres Libres, will be the only discourse capable of subverting the permanent link between prostitution and venereal diseases.

Key words: Prostitution, abolitionism, reglamentarism, hygienists doctors, Josephine Butler, sexuality

\section{INTRODUCCIÓN}

Hoy en día, se está desarrollando en el seno de muchos países occidentales un profundo debate en torno a la prostitución y, especialmente, a su regulación. Así pues, parecen repetirse argumentos en torno a la moral, el orden público y la salud pública (el SIDA en nuestro caso) que, si contemplamos la historia, no son en absoluto novedosos. Así pues, algunas asociaciones presionan para que las cosas cambien y desaparezca la prostitución como en su día desapareció la esclavitud y el trabajo de los menores de edad y, otras, por el contrario, luchan para que se reconozca la prostitución como un trabajo como otro cualquiera con su correspondiente reconocimiento de derechos laborales y civiles.

En este sentido, resulta sumamente interesante echar la vista atrás para estudiar y profundizar en las distintas respuestas que la sociedad ha dado a la prostitución a lo largo del tiempo por un doble motivo. En primer lugar, el proceso histórico nos ayuda a cuestionarnos y a librarnos de etiquetas estigmatizadoras que tanto excluyen a prostitutas o trabajadores sexuales. En segundo lugar, con la historia, pueden comprenderse mejor ciertas actitudes e incluso discursos que parecen rimar a lo largo del tiempo. Desde esta perspectiva, encontramos en el pasado tres actitudes o posturas respecto a este fenómeno en torno a las cuales va a girar este estudio.

En primer lugar, nos encontramos con los prohibicionistas. Este colectivo apostaba por un sistema mediante el cual la prostitución quedase prohibida y castigada con la cárcel. Además, incluía multas o medidas reeducadoras para quien la ejerciera, organizara o promoviera. Las razones que se argumentaban para esta decisión fueron, en la mayoría de las ocasiones, de índole moral. A todos los efectos, éste fue el marco normativo existente en España entre 1623 y 1845, desde que Felipe IV decidió comenzar a perseguir la prostitución hasta el establecimiento de los primeros códigos que regulaban, no prohibían, este fenómeno.

En segundo lugar, se desarrollan las ideas de los reglamentaristas. Defendían que la prostitución no debía ser proscrita sino que era necesaria 
su regulación mediante textos legales. Su opinión partía de la presunción de que la prostitución constituía un «mal social» inevitable, por tanto, para lograr el «bien común» y evitar pecados y excesos mayores era necesaria su contención. Este argumentario descansaba en la consideración de que hombres y mujeres tenían comportamientos sexuales diferenciados. Mientras que el hombre "necesitaba» una intensa actividad sexual, la mujer era más proclive a la contención. En este sentido, las prostitutas constituían una vía de escape para los hombres que, a su vez, permitía salvaguardar la virginidad y la decencia del resto de mujeres (doble moral sexual). Así mismo, mediante esta forma de actuación se pretendía controlar el contagio y la propagación de las enfermedades venéreas, en especial, de la sífilis. Este sistema ya había estado presente en España durante toda la Edad Media y parte de la Edad Moderna. Sin embargo, en la etapa contemporánea fue el método adoptado entre 1845 y 1935, esto es, entre el establecimiento de los primeros reglamentos y el decreto abolicionista aprobado en el transcurso de la II República; y también será el sistema que adoptó el franquismo entre 1941 y 1956. Como podemos observar, el prohibicionismo y el reglamentarismo fueron opciones en pugna hasta que, a mediados del siglo XIX, se acabó imponiendo el reglamentarismo.

Por último, nos encontramos con el abolicionismo. Los defensores de esta opción, salidos del movimiento feminista inglés (1869), surgieron como claros opositores al sistema reglamentarista. Justificaban su oposición al sistema imperante porque hacía recaer todo el peso del control sanitario y policial en la prostituta y no en el cliente masculino; era a la mujer a quien se recriminaba moralmente, le era recortada tremendamente su libertad y era marcada de por vida al quedar obligada a inscribirse en un registro administrativo. Además, éstos denunciaban y mostraban a la prostituta como una víctima del sistema moral y sexual existente en la época. Por el contrario, proponían el fin de la reglamentación y la integración de las prostitutas en un mercado laboral que les diera más oportunidades para subsistir (escasos salarios femeninos). Este será el sistema implantado por el decreto del 28 de junio de 1935 durante la II República.

En este sentido, podemos afirmar que el feminismo de finales del siglo XIX fue el causante del surgimiento de esta última opción, mientras que en el caso de las dos anteriores, el detonante había sido el discurso médicosocial. Así pues, se ha decidido dividir este artículo en dos apartados principales destinados a la explicación de estos discursos que conciernen al fenómeno prostitucional y que serán los encargados de influir, apoyar y 
ayudar a configurar las distintas iniciativas que tomaron los distintos poderes políticos en la materia que nos ocupa.

\section{El DisCURSO MÉDICO-SOCIAL}

Todos los higienistas y moralistas están contestes en que la prostitución es una enfermedad social, crónica e incurable, así como en la necesidad de buscar un tratamiento que atenúe las circunstancias del mal, ya que no otra cosa sea posible. ${ }^{2}$

\subsection{El nacimiento del higienismo como disciplina y su influencia en la cuestión femenina}

El movimiento teórico y médico-académico del higienismo fue fruto de la Ilustración y del liberalismo. Se configuró como un proyecto científicoburgués gestado en los círculos médicos desde finales del siglo XVIII a partir de la preocupación del sector médico por la higiene pública. ${ }^{3}$ Ésta era entendida, en palabras del higienista español Pedro Felipe Monlau (18081871), como «la referente a la conservación de la salud de las colecciones de individuos, de los pueblos, de los distritos, de los reinos, que estudia todas las causas de insalubridad pública, y consigna los preceptos oportunos para remediarlas». ${ }^{4}$

En este sentido, la preocupación tuvo su origen, por un lado, en las transformaciones derivadas del desarrollo de la vida urbana y en el impacto ocasionado por la Revolución Industrial; y, por otro lado, en las consecuencias evidentes que trajeron aparejadas estos cambios. La incidencia sobre las poblaciones, fundamentalmente urbanas, de enfermedades y epidemias (especialmente el cólera) provocaron altas tasas de mortalidad que, agravadas por el hacinamiento y la desnutrición, llevaron a

2 Prudencio Sereñana y Partagás, La prostitución en Barcelona estudiada como enfermedad social y considerada como origen de otras enfermedades dinámicas, orgánicas y morales de la población barcelonesa, Barcelona, Imp. de los Sucesores de Ramírez y C.a, 1882. No se va a paginar esta obra porque en su versión digitalizada no lo está. Tampoco lo está la de la Biblioteca Nacional ya que también poseen la versión digitalizada. Se ha decidido poner el capítulo de la obra en la que se sitúa lo citado, por ejemplo, en este caso («Introducción»).

3 Esteban Rodríguez Ocaña, La constitución de la Medicina Social como disciplina en España (1882-1923), Madrid, Ministerio de Sanidad y Consumo, 1987, p. 9.

4 Pedro Felipe Monlau, Elementos de higiene pública o Arte de conservar la salud de los pueblos, Tomo I, Madrid, Imprenta y Estereotipia de M. Rivadeneyra, 1862, p. 1. 
los médicos a realizar los primeros estudios dedicados a la cuestión que nos ocupa. ${ }^{5}$

En Europa, desde la publicación en 1790 de la obra del médico vienés Johann Peter Frank, La miseria del pueblo como madre de enfermedades, donde se denunciaba la pobreza y la miseria como causa permanente de enfermedad, ${ }^{6}$ otros higienistas como Turner Thackrah, Arnold, Chadwick, Villermé o Virchow contribuyeron con sus estudios a refundar la higiene dotándola de un cuerpo doctrinario propio y situándola en primera línea contra la lucha por la erradicación de las enfermedades y afecciones que se desarrollaban con más frecuencia en el medio urbano y que afectaban a la mayor parte de la población, especialmente, aquella conformada por las clases populares cuyas insalubres condiciones de vida y de trabajo se convertían en focos de enfermedad permanentes. Esto, a su vez, provocó que se estableciera en el seno de la disciplina una profunda relación de los profesionales de la medicina con la enfermedad propiamente dicha y con la problemática social de la población afectada. ${ }^{7}$

Dentro de este desarrollo, y respecto al tema que nos ocupa, nos encontramos con el higienista padre del reglamentarismo, el médico francés Alexandre Parent-Duchâtelet (1790-1836) cuya obra clave, De la prostitution dans la ville de Paris, fue publicada en 1836 de manera póstuma. ${ }^{8}$ Sus teorías fueron recogidas por médicos de casi todos los países europeos y acabaron configurando el sistema reglamentarista francés. La principal novedad que incluía esta corriente de pensamiento consistió en incorporar aspectos sociales a la vertiente meramente patológica de la medicina. ${ }^{9}$ Y esta incorporación es perfectamente observable en la obra de

5 «[en las ciudades] Allí se encuentra un foco perenne de enfermedades nerviosas y de epidemias; allí el asilo del crimen y de los vicios». Monlau, 1862, Tomo I, p. 87.

6 Carlos Medina-de la Garza y Martina Christine Koschwitz, «Johann Peter Frank y la medicina social», Medicina Universitaria, 52, 2011, p. 166.

7 Rafael Alcaide González, «La introducción y el desarrollo del higienismo en España durante el siglo XIX. Precursores, continuadores y marco legal de un proyecto científico y social», Scripta Nova, 3/50, 1999, p. 2.

8 Francisco Vázquez García, «Alexandre Parent-Duchâtelet y la actualidad de las políticas reglamentistas en materia de prostitución», en Ana Remón Rodríguez, Rosa María Toribio Ruiz y Francisco Vázquez García, De la prostitution dans la ville de Paris... (Col. Los Libros Olvidados. Biblioteca de la UCA, 2), Cádiz, Universidad, 2015, p. 5.

9 Gemma Nicolás Lazo, La reglamentación de la prostitución en el Estado español. Genealogía jurídico-feminista de los discursos sobre prostitución y sexualidad. Tesis doctoral inédita dirigida por Encarna Bodelón González y José Ignacio Rivera Beiras, Barcelona, Universidad de Barcelona, 2007. pp. 167-168. 
Parent-Duchâtelet; reconoce la difícil vida que soportan las mujeres de la clase obrera y lo difícil que les era obtener un trabajo bien remunerado y acaba concluyendo que la prostitución resultaba inevitable y, por tanto, la única forma de hacerle frente, y con ella a la sífilis, era su regulación. ${ }^{10}$

En este mismo sentido, los higienistas pensaban que su implicación en la sociedad debía ser profunda, aconsejando a los gobiernos sobre las normas jurídicas a aprobar para lograr el bienestar de la sociedad y de la población. A este respecto es reveladora la opinión manifestada por Pedro Felipe Monlau:

El higienista tiene el derecho de asesorar al Gobierno y a la Administración en todo lo que atañe a la salud pública: su voz es necesaria y competente en casi todos los ramos gubernativos y administrativos $[\ldots]^{11} \mathrm{El}$ médico-higienista debe mostrarse incansable en proponer, aconsejar e instar, todas las reformas y mejoras convenientes. ${ }^{12}$

Esta idea era fruto de la creencia de que el estado higiénico de una población resultaba determinante a la hora de evaluar la seguridad, la libertad y la comodidad de los pueblos. Por ello el higienismo propuso dos grandes grupos de medidas que deberían correr a cargo de los poderes públicos: el saneamiento del medio, en todas sus dimensiones, y un programa de moralización encaminado a educar a las clases populares en los preceptos higiénicos. ${ }^{13}$

Respecto al primer grupo de medidas, se entendía que el Estado debía ocuparse del mantenimiento de una higiene pública correcta, igual que las madres y las esposas se ocupaban de la higiene privada. Por ello, se debía obligar a algunos individuos a cumplir determinados códigos higiénicos si su situación iba a afectar a la salud pública; había que destruir las causas generales de insalubridad; $y$, finalmente, facilitar a los individuos enfermos los medios pertinentes para mejorar su situación. ${ }^{14} \mathrm{~A}$ pesar de estas recomendaciones, en muchas ocasiones, el Estado no estaba dispuesto a consumir un gran monto de recursos económicos en aplicar las medidas higiénicas que los médicos proponían.

10 Vázquez García, 2015: 6.

11 Monlau, 1862, Tomo I: 7-8.

12 Monlau, 1862, Tomo II: 1082.

13 Esteban Rodríguez Ocaña, «Paz, trabajo, higiene. Los enunciados acerca de la higiene industrial en la España del siglo XIX», en Rafael Huertas y Ricardo Campos, coords., Medicina social y clase obrera en España (siglos XIX y XX), Madrid, Fundación de Investigaciones Marxistas, $1992: 384$.

14 Monlau, 1862, Tomo I: 3-4. 
No obstante, y respecto al segundo grupo de medidas, el higienismo llevó a cabo una cruzada moralista fuertemente impregnada de la ideología burguesa que moldeó las formas de vida de la población decimonónica. ${ }^{15}$ En la consideración de que la prostitución era producto de la insensatez, la inmoralidad y la irreligiosidad inherentes en las clases populares, las mujeres que se dedicaban a la prostitución tendían a ser vistas como perezosas, ávidas de lujo o carentes de la suficiente devoción religiosa para luchar contra sus apetitos sexuales. ${ }^{16}$

Esta dualidad médico-social atrapó al higienismo en una contradicción interna entre, por un lado, su vocación de denuncia de las condiciones miserables en las que vivían las clases populares en las ciudades industriales y, por otro lado, su apuntalamiento del orden burgués mediante una serie de medidas que venían a paliar ciertas situaciones sociales pero que no atacaban los problemas de fondo, entre ellos, la estructura socio-económica imperante. ${ }^{17}$ En este sentido, el higienismo dirigió sus esfuerzos a controlar y racionalizar el espacio urbano de las ciudades para gestionar la marginalidad y tratar de eliminar o arrinconar los elementos peligrosos para la salud pública y, en consecuencia, para el orden social establecido. Por este motivo, los mendigos, los criminales, los vagabundos y las prostitutas fueron su objeto de preocupación principal. ${ }^{18}$

En este contexto de desarrollo y consolidación del higienismo, las mismas causas que produjeron el surgimiento de esta disciplina provocaron un nuevo impulso al debate plurisecular sobre la cuestión femenina. La discusión quedó integrada dentro del debate social que pretendía tratar los problemas demográficos, sanitarios y sociales en los que el papel y el puesto de las mujeres jugaban un papel fundamental.

Así pues, los problemas que planteaba la miseria fisiológica y la elevada mortalidad infantil llevaron a los médicos a preocuparse de manera

15 Rafael Alcaide González, «La higiene de la prostitución en Barcelona. Una aproximación a los contenidos médico-sociales del higienismo en España en el siglo XIX». En Prudencio Sereñana y Partagás, La prostitución en la ciudad de Barcelona, de Prudencio Sereñana y Partagás. [Barcelona, Imprenta de los sucesores de Ramírez y Cía, 1882] Edición y estudio introductorio por Rafael Alcaide. Barcelona, Universidad de Barcelona, p. 3.

16 Geraldine Scanlon, La polémica feminista en la España contemporánea (1868-1974), Madrid, Akal, 1986, p. 108.

17 Alcaide, 2000: 4.

18 Nicolás, 2007: 166. 
especial por la salud de las mujeres ya que su función reproductora implicaba que su bienestar fuera un requisito indispensable para lograr la salud de la especie. Se abrió entonces un nuevo campo de estudio para los investigadores médicos que debían buscar una manera de conciliar los «derechos de los niños» con los derechos de la mujer como individuo. En este sentido, podemos afirmar que la medicina, en la búsqueda de lograr la buena constitución del niño, contribuyó a colocar a la ciencia en la línea de defensa del orden patriarcal. Además, la disciplina científica, desplazando a la autoridad religiosa y la tradición, comenzó la tarea de demostrar que la especialización fisiológica del sexo femenino llevaba aparejada una especialización mental y, por tanto, la mujer sólo resultaba apta para la maternidad y la crianza. ${ }^{19} \mathrm{Y}$ el trabajo asalariado fue visto como un mal menor que conllevaba, en el caso de la mujer, una serie de riegos sanitarios, morales y sociales y, por lo tanto, una amenaza latente para la salud de la población futura.

Todo ello desembocó, a finales del siglo XIX, en una serie de medidas legislativas destinadas a la protección y restricción del trabajo femenino. Y provocaba que, en la mayoría de las ocasiones, la legislación, altamente influída por los postulados médico-higiénicos, no se ocupase de la protección de la mujer como individuo, sino como forma de proteger, en última instancia, el futuro de la especie.

Por tanto, nos encontramos que la prostituta era foco de atención, en este sentido, por dos motivos principales. En primer lugar, por su vinculación a los sectores marginales de las clases populares que eran considerados focos de transmisión de enfermedades y debían ser vigilados y reeducados en los principios del higienismo. En segundo lugar, por su propia naturaleza femenina: su modo de vida, su sexualidad alejada de la norma imperante y su actividad distanciada de la maternidad y la crianza la convertían en un sujeto a evitar y reconducir.

\subsection{La prostitución como foco de infección}

En este contexto de preocupación por la higiene pública, las enfermedades venéreas, junto con la tuberculosis y el alcoholismo, serán catalogados

19 Marie-Aline Barrachina, «Discurso médico y modelos de género», en Gloria Nielfa Cristóbal, coord.., Mujeres y hombres en la España franquista: sociedad, economía, política, cultura, Madrid, Universidad Complutense, 2003, pp. 68-70. 
como males 'sociales'.$^{20}$ Los médicos higienistas consideraban a este tipo de dolencias como peligrosas e inherentes a la sociedad..$^{21}$ Dentro de este marco discursivo, la vinculación de la prostitución con las enfermedades venéreas se consideró una relación causa-efecto, por tanto, un problema social y crónico. Así pues, la prostitución traía aparejada, inevitablemente, una serie de peligros: por un lado, diezmaba la salud y el vigor de la población por el contagio de enfermedades venéreas; y por el otro, teñía la sociedad de inmoralidad con actividades sexuales peligrosas e indecentes. ${ }^{22}$ Por tanto, el remedio debía pasar por la profilaxis como forma de evitar el contagio de enfermedades y por la educación moral como patrón de comportamiento social de las personas. ${ }^{23}$

Aunque estas consideraciones siempre constituyeron el fondo de la doctrina higiénica respecto a la prostitución, conforme transcurrió el último tercio del siglo XIX, este discurso médico-higienista fue adquiriendo un tono más alarmista en lo referente a los peligros económicos y demográficos que las enfermedades venéreas podrían tener sobre la población y las generaciones venideras. Entre ellas, sin duda, la sífilis, sucedió en el trono de los males terribles a enfermedades como la peste o la lepra y heredó de éstas su aura de peligrosidad universal y de símbolo de terror al contagio. Por tanto, como principal enfermedad venérea y como una de las más contagiosas en general, fue la más temida por los médicos. ${ }^{24}$

A mediados del siglo XIX, los conocimientos sobre la sífilis se basaban en la investigación empírica de Philippe Ricord y su Traité pratique des maladies vénériennes publicado en 1838 . En la indagación realizada en el Hôpital du Midi, el autor realizó unas 2500 inoculaciones en los pacientes del centro. A partir de sus experimentos en humanos, Ricord fue capaz de establecer unas pautas para distinguir la gonorrea de la sífilis y conceptualizar las características que presentaba esta última. Según este estudio, las autoridades médicas de mediados del siglo XIX estuvieron de acuerdo en afirmar que la sífilis era una enfermedad infecciosa que se transmitía a tra-

20 Ramón Castejón Bolea, «Enfermedades venéreas en la España del último tercio del siglo XIX: una aproximación a los fundamentos morales de la Higiene Pública», Dynamis, 11, 1991, p. 240.

21 Los higienistas pensaron que estas «enfermedades sociales» respondían a las alteraciones del orden económico, político y moral vigente (Rodríguez Ocaña, 1987: 23.

22 Monlau, 1862, Tomo I, p. 382.

23 Alcaide González, 1999, p. 21.

24 Judith Walkowitz, Prostitution and Victorian society: women, class, and the state, Cambridge, Cambridge University Press, 1980, p. 54. 
vés de la sangre mediante una herida. De la misma manera, establecieron que la forma más común de contagio era a través de las relaciones sexuales «impuras», es decir, fuera del matrimonio y de la norma sexual imperante. ${ }^{25}$ Así pues, prostitución (como modelo de sexualidad peligrosa), sífilis y enfermedad quedaron asociados irremediablemente.

$\mathrm{Al}$ establecerse esta vinculación, la prostitución quedó totalmente señalada como principal foco de este tipo de enfermedades. No obstante, la definición de la prostitución como principal germen de las enfermedades venéreas no estuvo únicamente sustentada por razones médicas, sino que, como ya hemos apuntado, incorporó razones de tipo moral muy evidentes. Esto se debió, en primer lugar, a la evidente relación entre enfermedades venéreas y sexualidad y, en segundo lugar, a que la prostitución contradecía la tesis que asociaba la salud de la nación con la disciplina sexual o con la sexualidad normalizada por la religión católica. Así pues, los médicos higienistas observaron las enfermedades venéreas no sólo como una patología sino también como un estigma, como la violación de la norma sexual imperante que contemplaba como legítimas las relaciones dentro del matrimonio y con fines reproductores. ${ }^{26}$

\subsection{Prohibicionistas y reglamentaristas en España}

Como hemos señalado, el higienismo estuvo de acuerdo en señalar a la prostitución como foco de infección. Sin embargo, no todos sus seguidores compartían una misma forma de actuación respecto a la prostitución, de modo que se constatan dos tendencias enfrentadas que protagonizaron importantes polémicas en este campo. Por un lado, se situaron los reglamentaristas, partidarios de regular la prostitución para contenerla y vigilarla. Por el otro, los prohibicionistas, partidarios de la supresión y persecución de esta actividad. En esta pugna en la que acabaron imponiéndose los primeros, los argumentos utilizados para defender una $u$ otra postura son sumamente reveladores.

En la primera parte del siglo XIX, destacaron en España cuatro higienistas: Ignacio María Ruiz de Luzuriaga, Mateo Seoane Sobral, Pedro Felipe Monlau y Francisco Méndez Álvaro. Entre ellos merece una especial mención Monlau, por ser el más prolífico en cuanto a producción literaria

25 Walkowitz, 1980 , p. 50.

26 Castejón, 1991, p. 242. 
y difusión de la doctrina higiénica. Nacido en Barcelona en 1808, cursó en esta ciudad sus estudios de medicina, licenciándose en 1831 y doctorándose en $1833 .^{27}$ Desde un primer momento desempeñó empleos de alto nivel como insignes puestos en distintas universidades, un cargo en el cuerpo de Sanidad Militar y una silla en el Consejo de Sanidad del Reino. ${ }^{28} \mathrm{Su}$ polifacética actividad le llevó a escribir más de medio centenar de libros y casi doscientos artículos originales o traducidos, consagrados a temas muy diversos. Destaca la publicación de Elementos de higiene pública o arte de conservar la salud de los pueblos (1847),, ${ }^{29}$ obra en la que el autor expone su postura prohibicionista y opina sobre el fenómeno prostitucional:

El oficio de prostituta es tanto o más infame que el de verdugo. Es el oficio más asqueroso, más impuro y más pútrido que se conoce [...] las incomodidades que su presencia causa a la sociedad, destruyendo la salud de los individuos, corrompiendo los manantiales de la procreación, sembrando el mal venéreo, influyendo fatalmente en la criminalidad y en la locura, disminuyendo la población $[\ldots]^{30}$

Como prohibicionista, Monlau apuesta por una persecución de la prostitución debido a causas que entremezclan las razones médicas con las morales. Relata en su obra la preocupación que siente por la extensión del contagio de la sífilis y propone como una de las medidas principales para frenarlo «corregir y perseguir la prostitución ${ }^{31} »$ por ser el principal foco de contagio. A continuación, sostiene su argumentación en su deseo de que la prostitución desaparezca, y propone una serie de medidas muy mediatizadas por la ideología típicamente burguesa:

La prostitución se corregirá naturalmente destruyendo sus causas. Edúquese a la juventud en los sanos principios de la higiene y la moral; vigílesela en las escuelas y en los talleres; inspírese amor al trabajo; difúndase la ilustración y el bienestar en todas las clases; prémiese la virtud; y la gangrena social de la prostitución quedará sumamente limitada y reducida. ${ }^{32}$

27 Ricardo Campos Marín, «Algunas reflexiones sobre la biografía divulgativa. Los casos de Monlau, Rubio y Giné», Asclepio, 57/1 (2005), p. 160.

28 Jorge Molero Mesa, «La tuberculosis como enfermedad social en los estudios epidemiológicos españoles anteriores a la Guerra Civil», Dynamis, 9, 1989, p. 187.

29 Alcaide, 1999 , p. 7-10.

30 Monlau, 1862, Tomo II, pp. 923-924.

31 Monlau, 1862, Tomo I, p. 383.

32 Monlau, 1862, Tomo I, p. 384. 
No obstante, el autor era muy consciente de que había otros médicos que no opinaban como él y que apostaban por una reglamentación «supuesto que la prostitución es incurable». Sin embargo, Monlau afirmaba que quienes se prestaban a este juego "prescinden de la moralidad, creyendo que entre la higiene y la moral hay alguna diferencia» ${ }^{33}$ y estos dos conceptos aparecen en su texto como las dos caras de una misma moneda.

Para Monlau la misión del gobierno no era regular lo que él consideraba un vicio, sino educar a los hombres en la virtud y en la continencia y perseguir a la mujer que pretendiera prostituirse. ${ }^{34}$. Pensaba que las causas más comunes por las que una mujer decidía prostituirse eran «la miseria, la ignorancia, la coquetería, las ganas de lucir y de brillar en vestidos y adornos, la pereza, el abandono». ${ }^{35} \mathrm{La}$ atención que requerían estas mujeres debía centrarse en proporcionarles una nueva educación y controlarlas con el objetivo de que no se volvieran a desviar.

Resulta evidente que para Monlau la moral y la higiene eran dos conceptos indisolubles, la una llevaba a la otra y viceversa. Y su postura prohibicionista y sus medidas de actuación contra la prostitución aparecen altamente mediatizadas por su ideología burguesa que tendió a imponer a las mujeres un modelo de sexualidad determinado y diferenciado del hombre. Esta misma ideología también fue proclive a considerar a las clases populares, y con ellas a las prostitutas, como ignorantes. Por ello resultaba preciso completar el programa higiénico con propuestas dirigidas a estos sectores en forma de receta moralizadora, resumida en la tríada orden, propiedad y mercado. ${ }^{36}$

Ante la existencia de una corriente reglamentarista, contraria a la defendida por Monlau, en 1847, se produjo el enfrentamiento, discursivamente hablando, con el también médico Juan Magaz y Jaime (1822-

33 Monlau, 1862, Tomo I, p. 385.

34 Ramón Castejón Bolea, "Las enfermedades venéreas: moral y sexualidad en la Medicina Social española», en Juan Atenza Fernández y José Martínez Pérez, El Centro Secundario de Higiene Rural de Talavera de la Reina y la Sanidad española de su tiempo, Toledo, Junta De Comunidades de Castilla-La Mancha, 2001, p. 152: Monlau, 1862, Tomo I, p. 408.

35 Monlau, 1862, Tomo II, pp. 924.

36 Esteban Rodríguez y Alfredo Menéndez, «Salud, trabajo y medicina en la España del siglo XIX. La higiene industrial en el contexto anti-intervencionista», Arch. Prev. Riesgos Labor, 8, 2005, p. 60. 
1901), firme defensor de la reglamentación de la prostitución ${ }^{37}$ y con otros seguidores de esta postura. Esta corriente mantenía que la prostitución era algo inherente a la sociedad y, por lo tanto, debía ser controlada y puesta bajo vigilancia para que las prostitutas pudieran ser inscritas en un registro, reconocidas médicamente y debidamente curadas en hospitales. ${ }^{38}$ En ese momento, por tanto, los dos discursos se encontraban en evidente pugna. Sin embargo, la evidente impronta de los ideales médicos partidarios del reglamentarismo en el primer texto que reguló la prostitución en Madrid ese mismo año, evidencia la tendencia que acabó imponiéndose.

Ello no obsta para que el magisterio ejercido por Monlau influyese decisivamente en la continuidad y definitivo arraigo de las doctrinas higienistas en España, especialmente en Madrid y Barcelona, que siempre estuvieron en vanguardia en lo referente a estudios científico-técnicos. La ciudad de Barcelona adquirió un notorio protagonismo por desarrollar en la segunda mitad del siglo XIX una intensa actividad intelectual en todos los ámbitos del pensamiento, incluido el proyecto intelectual higienista. Allí, un grupo de higienistas desarrollaron y sustentaron el sistema reglamentarista de la ciudad hasta su consolidación. Por tanto, si Monlau había vivido en unos tiempos de pugna entre prohibicionismo y reglamentarismo, en la segunda mitad del siglo XIX se produjo ya un clarísimo triunfo del reglamentarismo sustentado por las ideas higienistas.

Los principales representantes de este sistema triunfante se situaban, pues, en la ciudad de Barcelona. Había algunos seguidos de la obra de Monlau como Juan Giné Partagás (1836-1903), nacido en Cabra del Camp en 1836, que se licenció en Medicina en Barcelona en 1858 y se doctoró en Madrid en 1862; su carrera académica le llevó a ocupar la primera cátedra de Higiene de la Facultad de Medicina de Barcelona y, posteriormente, la de Clínica quirúrgica, siendo nombrado Decano de la misma Facultad en 1892. Antes de ocupar el decanato, en 1889, fue nombrado Director del Cuerpo Médico Municipal de Barcelona. ${ }^{39}$

37 Jean Louis Guereña, «Los orígenes de la reglamentación de la prostitución en la España contemporánea. De la propuesta de Cabarrús (1792) al Reglamento de Madrid (1847)», Dynamis, 15, 1995, p. 418.

38 Jean Louis Guereña, La prostitución en la España contemporánea, Madrid, Marcial Pons, 2003 , p. 71.

39 Campos, 2005, p. 161. 
Sin embargo, Giné no fue la única personalidad importante en el campo del higienismo en Barcelona. En esta misma línea destacó Prudencio Sereñana y Partagás, uno de los más famosos integrantes de la Sección de Higiene Especial (o de la prostitución) del Gobierno Civil de Barcelona desde $1880 .{ }^{40}$ Gracias a su experiencia y su contacto con la situación publicó en 1882 su emblemático libro La prostitución en la ciudad de Barcelona estudiada como enfermedad social y considerada como origen de otras enfermedades dinámicas, orgánicas y morales de la población barcelonesa. La publicación incluyó un prólogo muy interesante de Juan Giné Partagás. Ambos definieron los pilares básicos del reglamentarismo a la par que propusieron un reglamento mejorado para Barcelona a fin de que sustituyese al entonces vigente. En la propia introducción de la obra hallamos una justificación sobre la necesidad de publicación del estudio:

Mucho antes de ingresar en la Comisión de Higiene Especial de Barcelona, habíamos discutido diferentes veces en el seno de la confianza, con mi primo y maestro el Dr. Giné, acerca de la prostitución barcelonesa, y de si era susceptible de una reforma, bastante a satisfacer las exigencias de la moral y de la salud públicas. ${ }^{41}$

Como puede observarse, el autor tampoco diferencia entre moral e higiene. Esta opinión se encuentra en evidente conexión con la idea que mantenían los reglamentaristas; la regulación de la prostitución es la única opción para ejercer un mejor control moral, policial y sanitario sobre la misma ya que, en última instancia, ésta es inevitable. Esta inevitabilidad partía de la consideración de que mujeres y hombres poseían sexualidades diferenciadas, es decir, que mientras las mujeres eran más proclives a la moderación sexual, los hombres no podían controlar sus impulsos. Por tanto, la prostitución era la única vía de escape para que la mayoría de las mujeres se mantuvieran «puras» y prohibirla sólo podía desembocar en un aumento de la prostitución clandestina y, por tanto, de las enfermedades venéreas. El siguiente texto resulta revelador en este sentido:

El incesante vaivén de la política española es causa de un continuado cambio de personalidad en los Gobiernos de provincia, y la poca estabilidad de esas autoridades, ha dado siempre margen al desbarajuste que se observa en un ramo tan importante como es el de la Higiene especial, pues los múltiples negocios

40 Marisa Adriana Miranda, «Sobre las «asalariadas del amor»: prostitución y norma (Argentina y España)», Trabajos y comunicaciones, 42, 2015, p. 3.

41 Sereñana y Partagás, 1882: «Introducción». Disponible en: http://www.ub.edu/geocrit/ pspintro.htm 
provinciales absorben por completo a su Jefe. [...] las actuales leyes sobre la prostitución, aun cuando proporcionen algún resultado más positivo que en los tiempos en que se hallaba esta plaga completamente abandonada, no bastan a detener los incalculables daños que el venéreo y la sífilis están causando en la población. ${ }^{42}[\ldots]$ diremos: que la prostitución es una enfermedad de carácter social, consistente en el comercio que la mujer ejerce con su cuerpo, la cual, mediante una remuneración en dinero o en especie, se entrega al hombre para proporcionarle un goce sensual, permaneciendo, ella, pasiva en el acto. ${ }^{43}[\ldots]$ Consideramos aquella plaga, no como un mal necesario, pero si como un afecto inevitable. Bajo este concepto, creemos, no sólo conveniente, sino indispensable reglamentarla moral e higiénicamente. ${ }^{44}$

Así pues, para controlar a este colectivo "peligroso» en muchos sentidos, el autor proponía que el tratamiento de las prostitutas debía basarse en tres claves. La primera contemplaba remedios profilácticos entre los que se encontraban algunas medidas claramente progresistas para el momento. Entre ellas, las más importantes eran la instrucción obligatoria y gratuita de la mujer, un trabajo correctamente remunerado, el castigo al seductor en caso de abandono y la erradicación de la ociosidad de las mujeres. En segundo lugar, encontramos las propuestas moralistas como la creación de premios a la pureza de costumbres públicas y la formación de cátedras públicas dominicales para explicar las ventajas del trabajo y los peligros del vicio. En último lugar se sitúan las medidas paliativas que incluían la creación de hospitales de enfermedades venéreas y la provisión de más plazas para médicos higienistas. ${ }^{45}$

De este modo, el autor procede en su obra a la aplicación de estos principios en el diseño de un nuevo reglamento de higiene especial para Barcelona. Entre sus puntos claves estaban, por ejemplo:

Art. 4. El ingreso de una mujer en la prostitución, será voluntario o de oficio. Para ingresar voluntariamente, deberá firmar la interesada una hoja-demanda [una cartilla] [...]. Será inscrita de oficio, la mujer que se dedique de un modo notorio a la prostitución, siendo circunstancia decisiva, el haber sido arrestada por actos de libertinaje o sufrido enfermedad venérea.

42 Sereñana y Partagás, 1882: I Parte: «V. De la prostitución en España». http://www. ub.edu/geocrit/psp15.htm

43 Sereñana y Partagás, 1882: II Parte: «I. Definición y formas de la prostitución». http:// www.ub.edu/geocrit/psp21.htm

44 Sereñana y Partagás, 1882: «Conclusiones». http://www.ub.edu/geocrit/pspconc.htm

45 Sereñana y Partagás, 1882: II Parte «VII. Tratamiento». http://www.ub.edu/geocrit/ psp27.htm 
Art. 11. Las prostitutas quedan en libertad de asistir a los espectáculos públicos, concurrir a los paseos y discurrir por todas las calles y lugares a todas horas, siempre y cuando vayan acompañadas de un hombre y guarden la decencia y compostura propia de las personas honestas. Sin embargo, podrán salir solas las prostitutas, de doce a dos de la noche, en verano, y de once a una en invierno.

Art. 24. Todas las prostitutas serán visitadas dos veces por semana o más, si se juzgare necesario. ${ }^{46}$

Por tanto, se observa que las líneas maestras de este proyecto eran las líneas maestras de los reglamentaristas y combinaban tanto el control policial destinado a recluir y marginar a las prostitutas restringiendo sus derechos como ciudadanas como el control médico mediante la revisión médica para que no constituyeran un peligro para sus semejantes. Este tipo de medidas fueron comunes a la mayoría de los reglamentos que se implantaron en las ciudades españolas a lo largo del siglo XIX.

En este sentido, los higienistas, y especialmente dentro de ellos los reglamentaristas, no dudaron en sustentar una política que señalaba a la prostituta como reservorio de las enfermedades venéreas y que confiaba en la regulación de esta actividad como la más adecuada para hacer frente a lo que ellos consideraban un creciente problema. ${ }^{47}$ Merece la pena destacar que dentro de este discurso médico-moral, los principales responsables del contagio eran los hombres casados y las prostitutas, ya que habían contraído la enfermedad por voluntad propia y, además, constituían los principales focos de infección dentro de su familia o su comunidad. No obstante, la responsabilidad no era distribuida a partes iguales pues eran las prostitutas, y especialmente las clandestinas, ${ }^{48}$ las más estigmatizadas por quedar consideradas como contaminadoras de la masculinidad y de la eficiencia de la especie. ${ }^{49}$ Todo ello hacía que primaran los discursos basados en la regeneración moral y la abstención sexual sobre la difusión de la profilaxis individual tanto física (preservativo) como química. ${ }^{50}$

46 Sereñana y Partagás, 1882: II Parte «VII. Tratamiento». Los tres fragmentos. http:// www.ub.edu/geocrit/psp27.htm

47 Ramón Castejón Bolea, «Las enfermedades venéreas y la regulación de la sexualidad en la España contemporánea», Asclepio, vol. 56/2, 2004, p. 225.

48 Sereñana y Partagás, 1882: «Introducción». http://www.ub.edu/geocrit/pspintro.htm

49 Castejón Bolea, 2004, p. 234.

50 Castejón Bolea, 2004, p. 238. 


\section{El FEMINISMO EN INGLATERRA, CUNA DEL ABOLICIONISMO}

Las prostitutas son, realmente, en toda la terrible acepción de la palabra, las ex mujeres, y, a pesar de los himnos entonados en su honor, $[\ldots]$ las prostitutas siguen estando, fuera, al margen de la vida.

Margarita Nelken ${ }^{51}$

El abolicionismo como ideología y movimiento político de corte feminista que intentaba denunciar el sistema reglamentarista de la prostitución tuvo su origen en la Gran Bretaña de los años sesenta y setenta del siglo XIX. Se enmarcó dentro del amplio movimiento feminista presente en este país durante toda la centuria con el objetivo de, en última instancia, desarticular la ideología de la naturaleza diferente y complementaria de los sexos.

Esto significaba enfrentarse a las grandes figuras de autoridad de la Ilustración y a lo que se percibía como algo natural, es decir, las grandes diferencias entre capacidades y aspiraciones de hombres y mujeres. En este sentido, las luchas de las sufragistas fueron, en buena parte, una pelea por desactivar los ancestrales perjuicios que pesaban sobre la naturaleza de las mujeres. Dentro de este amplio movimiento existieron distintas luchas que se ocupaban del cuestionamiento de distintas facetas del orden patriarcal. Y una de ellas fijó su atención en la ideología sobre la prostitución. ${ }^{52}$

En aquellos años, el público británico no estaba acostumbrado a mujeres que hablasen públicamente sobre cuestiones tales como la prostitución, las enfermedades venéreas y los exámenes ginecológicos internos. ${ }^{53} \mathrm{La}$ sociedad victoriana imponía un férreo tabú sobre cualquier cuestión referente a la sexualidad, y más, si estas cuestiones eran tratadas por mujeres ya que eran consideradas actividades poco respetables ${ }^{54}$.

Así, este movimiento político denominado como abolicionismo surgió como consecuencia de la promulgación en Inglaterra de una serie de leyes

51 Margarita Nelken, La condición social de la mujer en España. Su estado actual; su posible desarrollo, Barcelona, Horas y Horas, 2012, p. 117.

52 Ana de Miguel Álvarez y Eva Cermeño Palomo, «Los inicios de la lucha feminista contra la prostitución: políticas de redefinición y políticas activistas en el sufragismo inglés», Brocar, 35, 2011, pp. 318-319.

53 Walkowitz, 1980: p. 93.

54 De Miguel Álvarez y Cermeño, 2011, p. 323. 
— conocidas como Leyes de Enfermedades Contagiosas en 1864, 1866, y $1869^{55}$ - , que pretendían frenar el contagio de enfermedades venéreas en el ejército, por constituir la salud y la protección de los miembros de este cuerpo una preocupación de primer orden.

La promulgación de la última de estas leyes, la de 1869, desencadenó un movimiento de protesta de gran envergadura. ${ }^{56}$ Esta normativa establecía la posibilidad de que cualquier mujer presente en determinados recintos militares, sospechosa de ser prostituta, podía ser detenida y llevada ante una autoridad jurídica para que determinase su condición. Si el resultado era positivo, podía ser sometida a un examen médico forzoso y tratada en un hospital en caso de hallarse afectada por alguna enfermedad venérea. Aunque en principio la ley sólo era de aplicación en las guarniciones militares, existía la clara voluntad de extenderla al resto de colectivos sociales de naturaleza civil. Este tipo de medidas recibieron el apoyo de los hombres de clase media y alta, y también fueron sustentadas por liberales y médicos que anteponían la necesidad de frenar la mortalidad por enfermedades venéreas a los derechos civiles de las mujeres. ${ }^{57}$

En torno a estas medidas se conformó un movimiento de protesta integrado por inconformistas, feministas y trabajadores radicales pertenecientes a las clases medias que catalogaron estas leyes como inmorales y contrarias a los derechos civiles de las mujeres ${ }^{58}$ apostando por su derogación. Para articular la lucha se fundó, a finales de ese mismo año, la Ladies $\mathrm{Na-}$ tional Association for the Repeal of the Contagious Diseases Acts (LNA). Desde dentro, Elizabeth Wolstenholme, una comprometida activista feminista, entró en contacto con Josephine Butler (1828-1906), ${ }^{59}$ otra feminista

55 Paul Mchugh, Prostitution and Victorian social reform, London, Routledge, 2013, pp. 40-50.

56 Mercedes Rivas Arjona, «II República española y prostitución: el camino hacia la aprobación del Decreto abolicionista de 1935", Arenal, 20, 2013, p. 350.

57 Nancy Boyd, Josephine Butler, Octavia Hill, Florence Nightingale: three Victorian women who changed their world, London, Macmillan Press, 1984, pp. 40-41.

58 Por ejemplo, se referían a la inspección médica forzosa de las mujeres como una «violación instrumental». Judith Walkowitz, «Vicio masculino y virtud feminista: el feminismo y la política sobre la prostitución en Gran Bretaña en el siglo XIX», en James Amelang y Mary Nash, Historia y género: las mujeres en la Europa moderna y contemporánea, Valencia, Alfons el Magnànim, 1990, p. 217.

59 Pertenecía a una familia acomodada de propietarios con fuertes convicciones cristianas basadas en la tolerancia y la libertad de conciencia, y comprometida al mismo tiempo con las ideas liberales. De Miguel y Cermeño, 2011, p. 323. 
muy bien relacionada con el mundo protestante ${ }^{60}$ y dedicada, hasta ese momento, al fomento de la educación superior de las mujeres y a la búsqueda de mayores oportunidades laborales para las mismas. ${ }^{61} \mathrm{Y}$ le pidió a Butler que organizase una campaña femenina contra estos dictámenes. ${ }^{62}$

A partir de este momento, Butler tomará el control de la organización que denunciará, en su Manifiesto de las Damas, la doble moral que venía a sancionar esta normativa. Los que estaban a favor de esta causa mantenían que las leyes implantadas no tenían ningún problema en facilitar el acceso de los hombres a la prostitución pero, sin embargo, criminalizaban a las mujeres por implicarse en estas mismas actividades. ${ }^{63}$ Además, estas mujeres feministas entendían que las causas que empujaban a las mujeres pobres a trabajar como prostitutas eran los bajos salarios y las restricciones al empleo femenino: por ello debían recurrir a empleos mejor pagados como la prostitución. Por tanto, estas activistas, en la idea de que la prostitución era un problema que afectaba básicamente a mujeres de la clase trabajadora, se consideraron, a sí mismas, las más indicadas para defender sus derechos. De modo que, aunque pretendieron protegerlas, también establecieron relaciones jerárquicas y de tutelaje sobre ellas. ${ }^{64}$

Las protestas organizadas por Josephine Butler y los defensores del abolicionismo continuaron mediante la publicación, en el Daily Nerws, de un manifiesto que iba más allá y atacaba el sistema reglamentarista de la prostitución en sí mismo. El manifiesto, apoyado por 124 firmas de importantes feministas y mujeres destacadas, explicaba e insistía en la idea de que el sistema vigente suponía la violación de los derechos civiles de las mujeres y sancionaba una actividad basada en el vicio y la doble moral. ${ }^{65}$ Con el objetivo de conseguir la abolición del reglamentarismo, las feministas realzaron

60 Guereña, 1995, p. 641.

61 Butler llegó a ser la presidenta del North of England Council for Promoting the Higher Education of Women. Cf. Mchugh, 2013, p. 15.

62 Elizabeth Wolstenholme defendía el movimiento contra estas leyes como «la cruzada moral del siglo XIX», según recoge el estudio de Maureen Wright, Elizabeth Wolstenholme Elmy and the Victorian Feminist Movement. The biography of an insurgent woman, Manchester, Manchester University Press, 2011, p. 10.

63 Aunque vamos a hacer hincapié en su vertiente relacionada con el abolicionismo de la prostitución, autores tan importantes como Richard Evans la consideran la mayor representante del feminismo moral internacional. Richard Evans, Las feministas: los movimientos de emancipación de la mujer en Europa, América y Australasia, 1840-1920, Madrid, Siglo Veintiuno, 1980, p. 78.

64 Walkowitz, 1990, pp. 218-219.

65 Boyd, 1984, pp. 42-45. 
el discurso que dibujaba a la prostituta como una víctima inocente de la lujuria del hombre y de la tiranía médica y policial a la que el hambre había empujado a aquella situación. Lógicamente, este planteamiento dejó de lado la discusión sobre la prostitución voluntaria, ya que trastocaba su línea ideológica. Por tanto, y en este sentido, este grupo de mujeres feministas se vio en parte limitado por los perjuicios de su propia clase social, que tendía a localizar a la mujer como un ser puro e indefenso atacado por el varón. ${ }^{66}$

El movimiento logró encontrar apoyos en la clase obrera aunque había discrepancias a la hora de defender la liberalización del trabajo femenino por la que apostaban las abolicionistas. Una parte de la clase obrera consideraba que el problema de la prostitución no residía en la falta de trabajo femenino, sino en el empobrecimiento de la familia trabajadora debido al bajo salario del hombre adulto que debía competir con mujeres y niños - la defensa del llamado «salario familiar». ${ }^{67}$ No obstante, para 1871, se habían formado cincuenta y siete sucursales de la LNA, con un total de 811 miembros inscritos.

Por su parte, Butler no sólo se centró en luchar contra este sistema en su país. En 1874 viajó a París con la clara idea de comenzar una gira por el continente exponiendo sus ideas. Así nació, en 1875, la Internacional Abolitionist Federation, una organización que se declaró independiente de cualquier partido político y que reunió en su seno a personas de diferente sensibilidad ideológica como racionalistas, humanistas, librepensadores o religiosos (anglicanos, protestantes y evangelistas). Todos ellos compartían la idea de que la prostitución era producto de la sociedad, de manera que la única forma de acabar con la misma pasaba por lograr que las mujeres de las clases inferiores tuvieran los suficientes medios a su alcance para poder mantenerse mediante otras opciones laborales. ${ }^{68}$ Además, sus argumentos insistieron en la ineficacia del sistema vigente y la doble moral que escondía pues convertía a la prostituta en un sujeto estigmatizado al señalarla mediante un documento oficial o cartilla que el hombre no recibía, a pesar de contribuir con sus visitas a la continuidad de este círculo. ${ }^{69}$ Las

66 Walkowitz, 1990, p. 239.

67 No obstante, no se veía a los hombres y mujeres de la clase obrera como aliados, sino como meros apoyos necesarios y objeto de interés. Cf. Walkowitz, 1990, pp. 222-223.

68 María José Lacalzada de Mateo, Mentalidad y proyección social de Concepción Arenal, Ferrol, Cámara Oficial de Comercio, Industria e Navegación, 1994, p. 352.

69 Rosa María Capel Martínez, «La prostitución en España: notas para un estudio sociohistórico», en Rosa María Capel Martínez (coord.), Mujer y sociedad en España (17001975), Madrid, Instituto de la Mujer, 1986, pp. 295-296. 
acciones que propusieron fueron de dos tipos: instruir y moralizar a las mujeres, por un lado, e incorporarlas al mundo del trabajo en mejores condiciones, por el otro. Esta propuesta permite deducir que las abolicionistas, a pesar de ser conscientes de la discriminación que imponía la legislación a las mujeres, seguían siendo hijas de los valores burgueses basados en el trabajo y la moral.

Además de crear la Federación Abolicionista, con el objetivo de seguir extendiendo sus ideas, Josephine Butler publicó en 1875 su obra referente en esta materia, Une voix dans le désert. Traducida a un buen número de idiomas, le permitió difundir su pensamiento por el continente europeo. En ella, Butler realizó una auténtica declaración de intenciones sobre los objetivos que persigue, expresando el argumentario básico del abolicionismo, denunciando las prácticas reglamentaristas, reivindicando la intervención femenina en política y defendiendo la nueva forma de concebir el fenómeno prostitucional. En la siguiente selección de fragmentos de su obra se encuentran los principales pilares de su pensamiento:

En medio de la apatía general, es bueno atraer a los espíritus a considerar la prostitución desde otro punto de vista que la del materialismo. ${ }^{70}[\ldots]$ Las medidas disciplinarias ideadas por la Policía de las costumbres se dirigen exclusivamente contra el sexo débil [...] Sólo hay una explicación plausible [...] los reglamentos de la Policía fueron hechos por hombres, [...] sin tener en cuenta los derechos naturales o la dignidad de las mujeres. No existen dos leyes morales, uno para el sexo fuerte y otra para el sexo más débil. [...] Circunstancias accidentales de la escuela, la muerte de un padre o una madre, la ociosidad forzada, el salario insuficiente, la pobreza, las falsas promesas, seducciones, las trampas debajo de sus pies, tales son las causas [...] La situación se convertirá en otra cuando se abandone la actividad caritativa, y se adopte una actitud militante contra la prostitución legal. ${ }^{71}$

Con el mismo objetivo de extender sus ideas un órgano de prensa específico, la Federación creó Le Bulletin Continental y organizó una serie de congresos como medio de aunar a todas las federaciones presentes en los distintos países europeos y entablar debates científicos que contribuyeran

70 Josephine Butler, Une voix dans le desert. Moralité publique, Neuchâtel, Bureau du Bulletin Continental, 1876, p. 4. (He traducido la obra y la he paginado como el original de esta segunda edición disponible en la Biblioteca Nacional de Francia.) Con 'materialismo', Butler se refiere a la concepción de que la prostitución es algo inevitable y permanente.

71 Butler, 1876, pp. 10, 14, 23, 32-33, 56. 
a la extensión del abolicionismo. ${ }^{72}$ La propagación de estas ideas motivó que en 1877 apareciese una traducción al español de la obra de Josephine Butler bajo el título Moralidad pública. Una voz en el desierto y que, ese mismo año, se celebrase en Ginebra el primer Congreso Internacional de la Federación Abolicionista, al que acudieron representantes de las federaciones de Francia, Suiza, Italia, Alemania y Holanda. ${ }^{73}$

Dentro del paradigma liberal, las ideas abolicionistas pueden ser consideradas de carácter progresista por una serie de razones. En primer lugar, la realización de estudios sobre las condiciones de vida de las obreras que promovieron un conjunto de iniciativas dentro de la esfera política; en segundo lugar, la incorporación de las mujeres de clase alta y media a un trabajo de carácter social a la vez que intentaba incorporar a las mujeres a un trabajo productivo; y en tercer y último lugar, las reformas en la legislación para favorecer la igualdad de oportunidades. ${ }^{74}$

Aunque es innegable la influencia de las ideas defendidas por Butler en Europa, no fue lo suficientemente intensa como para provocar cambios inmediatos. Aparte de la suspensión de la Ley de Enfermedades Contagiosas en Inglaterra en 1883 y su derogación definitiva en 1886, Butler y sus partidarios no pudieron evitar que, al final de la década de los ochenta, el debate sobre el sexo fuera monopolizado por expertos profesionales masculinos, eclesiásticos conservadores y partidarios de la pureza social. ${ }^{75} \mathrm{Ni}$ tampoco lograron impedir la intensificación de la represión contra prostitutas y burdeles. ${ }^{76}$ En el continente, el sistema reglamentarista francés logró salir libre del desafío. El único éxito palpable fue la abolición de la prostitución en 1907 en la Suiza calvinista. ${ }^{77}$ En este sentido, el discurso feminista puede considerarse que resultó minoritario, aunque su influencia iba a revelarse fundamental a largo plazo, siendo ejemplo de ello la instauración del abolicionismo en España con la llegada de la II República. ${ }^{78}$

72 Lacalzada, 1994, pp. 352-353.

73 Jean-Louis Guereña, «La masonería española frente a la prostitución durante la Restauración», en José Antonio Ferrer Benimeli, coord., La masonería española en el 2000: una revisión histórica, Zaragoza, Gobierno de Aragón, 2001. Vol. 2, p. 644.

74 Lacalzada, 1994, pp. 354-355.

75 Walkowitz, 1990, pp. 223-236.

76 Walkowitz, 1980, p. 23.

77 Evans, 1980, pp. 157-158.

78 Decreto del 28 de junio de 1935. 


\section{Conclusiones}

La respuesta ante la incidencia de las enfermedades venéreas ha estado presente en el conjunto de discursos que han construido y regulado la sexualidad en la sociedad occidental moderna. En este ensayo hemos tratado de analizar la vinculación en esos discursos de las enfermedades venéreas con la prostitución y con los problemas de salud pública en la España contemporánea. Tales vínculos ofrecieron una poderosa legitimación para la regulación y la construcción social de la prostitución no sólo como foco infeccioso sino también como un tipo de sexualidad "peligrosa», contraria a la sexualidad normalizada por la religión católica. En este sentido, las mujeres sexualmente activas quedaron estigmatizadas como reservorio de las enfermedades venéreas.

Desde este discurso, el tratamiento y la propaganda dispensada desde los centros médicos apoyados por doctores higienistas se instrumentalizaron para acometer un programa de «moralización» entre las clases populares. Así pues, se produjo un trasvase de los valores de las clases medias moderación, auto-control, abstinencia e higiene- a las clases populares justificado, fundamentalmente, por la imagen negativa que se tenía de estos grupos sociales como focos de pobreza y, por tanto, de problemas. Y en este contexto la prostituta debía ser tenida en cuenta por un doble motivo: en primer lugar, por su vinculación a sectores marginales y pobres de la sociedad y, en segunda instancia, por esta sexualidad activa y alejada de la norma que practicaba.

El sistema reglamentarista fue la plasmación de esta serie de valores defendidos por la ideología burguesa y contenidos en la doctrina higienista. Se trató de configurar un plan que tenía un marcado carácter de género y que estaba sustentado en la creencia de que hombres y mujeres no poseían sexualidades del mismo tipo: la mujer, procreadora nata, era más dada a la contención, mientras que el hombre difícilmente podía retener sus impulsos sexuales. Por tanto, para el mantenimiento del sistema, la prostitución constituyó un mal necesario, una válvula de escape perfecta para que el orden establecido no se alterase ni colapsara.

Ante este enfoque surgieron alternativas que pretendieron derrumbar la configuración del sistema reglamentarista, así como cambiar los principales pilares ideológicos que lo sustentaban. Desde el feminismo se elaboró una alternativa que aspiraba a acabar con la discriminación de las prostitutas frente a sus clientes en materia sanitaria y que consideraba esta actividad como un modo de vida no lícito con el que era necesario y posible acabar a 
través de la implantación de programas de educación y con la oferta de empleos dignos y bien remunerados para las mujeres de las clases trabajadoras. No obstante, esta alternativa también estaba impregnada de un marcado carácter burgués ya que, en última instancia, pretendía ejercer unas determinadas funciones de tutelaje y establecía una primacía sobre estas mujeres prostitutas pertenecientes a las clases trabajadoras: y, además, no desvinculaba a este colectivo de su relación con las enfermedades venéreas, considerando que el problema existía aunque, en su solución, planteasen otras alternativas más allá del reglamentarismo.

El anarquismo - y especialmente en España la organización feminista Mujeres Libres (1936-1939) ${ }^{79}$ — será entre todas las alternativas analizadas, la que más transgredió el discurso imperante en la época. Hasta entonces, nadie se había atrevido a desvincular la prostitución de las enfermedades venéreas ni a intentar solucionar la cuestión de manera individualizada, sin unirlo a otros conflictos de carácter sanitario. Así mismo, al defender un modelo de sexualidad diferente para la mujer - y en paralelo al modelo sexual masculino-, los presupuestos anarquistas trataron de evitar la estigmatización del colectivo y asumieron que las mujeres que ejercían la prostitución no lo harían si contasen con la posibilidad de una buena educación y la oportunidad de incorporarse al mundo como trabajadoras de pleno derecho. La alternativa anarquista contenía, por tanto, propuestas que partían desde un punto de vista igualitario y de socorro a la prostituta y no, como en las otras opciones expuestas en este ensayo, desde unas premisas de tutelaje y jerarquía. Al menos, en la teoría.

\section{REFERENCIAS BIBLIOGRÁFICAS}

ACKelsberg, Martha, 1999, Mujeres Libres: El anarquismo y la lucha por la emancipación de las mujeres. Barcelona, Virus. [Free Women of Spain. Anarchism and the Struggle for the Emancipation of Women, Bloomington, Indiana University Press, 1991].

79 Pueden consultarse, entre otros estudios sobre el tema: Mary Nash, ed., Mujeres Libres: España 1936-1939. Barcelona, Tusquets, 1975; Martha Ackelsberg, Mujeres Libres: El anarquismo y la lucha por la emancipación de las mujeres. Barcelona, Virus, 1999 [Free Women of Spain. Anarchism and the Struggle for the Emancipation of Women, Bloomington, Indiana University Press, 1991]; Laura Sánchez Blanco, «El anarcofeminismo en España: las propuestas anarquistas de mujeres libres para conseguir la igualdad de géneros», Foro de educación, 9 (2007), pp. 229-238. 
AlCAide GonZÁlez, Rafael, 1999, «La introducción y el desarrollo del higienismo en España durante el siglo XIX. Precursores, continuadores y marco legal de un proyecto científico y social», Scripta Nova. Revista electrónica de geografía y ciencias sociales, 3/50: 32-54.

Alcaide GonzÁlez, Rafael, 2000, «La higiene de la prostitución en Barcelona. Una aproximación a los contenidos médico-sociales del higienismo en España en el siglo XIX». En Prudencio Sereñana y Partagás, La prostitución en la ciudad de Barcelona, de Prudencio Sereñana y Partagás. [Barcelona, Imprenta de los sucesores de Ramírez y Cía, 1882] Edición y estudio introductorio por Rafael Alcaide. Barcelona, Universidad de Barcelona, Colección Geocrítica. Textos electrónicos.

BARRACHINA, Marie-Aline, 2003, «Discurso médico y modelos de género». En Gloria Nielfa Cristóbal, coord., Mujeres y hombres en la España franquista: sociedad, economía, politica, cultura. Madrid, Universidad Complutense: 67-94.

BOYD, Nancy, 1984, Josephine Butler, Octavia Hill, Florence Nightingale: three Victorian women who changed their world. London, Macmillan Press.

Butler, Josephine, 1876, Une voix dans le desert. Moralité publique. Neuchâtel, Bureau du Bulletin Continental.

CAMpos MArín, Ricardo, 2005, «Algunas reflexiones sobre la biografía divulgativa. Los casos de Monlau, Rubio y Giné», Asclepio. Revista de historia de la medicina y de la ciencia, 57/1: 149-166.

CAPEl Martínez, Rosa María, 1986, «La prostitución en España: notas para un estudio socio-histórico». En María José Durán Heras y Rosa María Capel Martínez, coord., Mujer y sociedad en España (1700-1975). Madrid, Instituto de la Mujer: 265-298.

CASTEjón Bolea, Ramón, 1991, «Enfermedades venéreas en la España del último tercio del siglo XIX: una aproximación a los fundamentos morales de la Higiene Pública», Dynamis. Acta hispanica ad medicinae scientiarumque historiam illustrandam,11: 239-262.

CASTEJÓn BoleA, Ramón, 2001, «Las enfermedades venéreas: moral y sexualidad en la Medicina Social española». En Juan Atenza Fernández y José Martínez Pérez, coords., El Centro Secundario de Higiene Rural de Talavera de la Reina y la Sanidad española de su tiempo. Toledo, Junta De Comunidades de CastillaLa Mancha: 149-171.

CASTEJÓn BoleA, Ramón, 2004, «Las enfermedades venéreas y la regulación de la sexualidad en la España contemporánea», Asclepio. Revista de historia de la medicina y de la ciencia, 56/2: 223-242.

De Miguel Álvarez, Ana y Eva Cermeño Palomo, 2011, «Los inicios de la lucha feminista contra la prostitución: políticas de redefinición y políticas activistas en el sufragismo inglés", Brocar. Cuadernos de investigación bistórica, 35: 315-334.

Evans, Richard, 1980, Las feministas: los movimientos de emancipación de la mujer en Europa, América y Australasia, 1840-1920. Madrid, Siglo Veintiuno. 
GuEREÑA, Jean Louis, 1995, «Los orígenes de la reglamentación de la prostitución en la España contemporánea. De la propuesta de Cabarrús (1792) al Reglamento de Madrid (1847)», Dynamis, Acta hispanica ad medicinae scientiarumque historiam illustrandam 15, 401-441.

GuEREÑA, Jean Louis, 2001, «La masonería española frente a la prostitución durante la Restauración». En José Antonio Ferrer Benimeli, coord., La masonería española en el 2000: una revisión histórica (IX Symposium internacional de historia de la masonería española, Segovia, septiembre de 2000). Zaragoza, Gobierno de Aragón. Vol. 2: 641-662.

GuereÑa, Jean Louis, 2003, La prostitución en la España contemporánea. Madrid, Marcial Pons.

Lacalzada de Mateo, María José, 1994, Mentalidad y proyección social de Concepción Arenal. Ferrol, Cámara Oficial de Comercio, Industria e Navegación.

Mchugh, Paul, 2013, Prostitution and Victorian social reform. London, Routledge.

Medina de la Garza, Carlos y Martina Christine Koschwitz, 2011, «Johann Peter Frank y la medicina social», Medicina Universitaria, 52: 163-168.

MirAndA, Marisa Adriana, 2015, «Sobre las «asalariadas del amor»: prostitución y norma (Argentina y España)», Trabajos y comunicaciones, 42. http://www. trabajosycomunicaciones.fahce.unlp.edu.ar/issue/view/274

Molero MesA, Jorge, 1989, «La tuberculosis como enfermedad social en los estudios epidemiológicos españoles anteriores a la Guerra Civil», Dynamis. Acta bispanica ad medicinae scientiarumque historiam illustrandam, 9: 185-224.

Monlau y Roca, Pedro Felipe, 1862, Elementos de higiene pública o Arte de conservar la salud de los pueblos. Tomo I. Madrid, Imprenta y Estereotipia de M. Rivadeneyra.

NASH, Mary, ed., 1975, Mujeres Libres: España 1936-1939. Barcelona, Tusquets.

Nelken, Margarita, 2012, La condición social de la mujer en España. Su estado actual; su posible desarrollo. Barcelona, Horas y Horas.

NicolÁs LAZO, Gemma, 2007, La reglamentación de la prostitución en el Estado español. Genealogía jurídico-feminista de los discursos sobre prostitución y sexualidad. Tesis doctoral inédita dirigida por Encarna Bodelón González y José Ignacio Rivera Beiras. Barcelona, Universidad de Barcelona.

Rivas ArJONA, Mercedes. 2013, «II República española y prostitución: el camino hacia la aprobación del Decreto abolicionista de 1935», Arenal. Revista de historia de las mujeres, 20/2: 345-368.

Rodríguez Ocaña, Esteban, 1987, La constitución de la Medicina Social como disciplina en España (1882-1923). Madrid, Ministerio de Sanidad y Consumo.

Rodríguez OcAÑA, Esteban, 1992, «Paz, trabajo, higiene. Los enunciados acerca de la higiene industrial en la España del siglo XIX». En Rafael Huertas y Ricardo Campos Marín, coords., Medicina social y clase obrera en España (siglos XIX $y X X)$. Madrid, Fundación de Investigaciones Marxistas. Vol. 2: 383-400. 
RodrígueZ, Esteban y Alfredo MENÉndeZ, 2005, «Salud, trabajo y medicina en la España del siglo XIX. La higiene industrial en el contexto anti-intervencionista», Archivos de Prevención de Riesgos Laborales, 8: 58-63.

SÁNCHEZ BlANCO, Laura, 2007, «El anarcofeminismo en España: las propuestas anarquistas de mujeres libres para conseguir la igualdad de géneros», Foro de educación, 9: 229-238.

SCANLON, Geraldine,1986, La polémica feminista en la España contemporánea (1868-1974). Madrid, Akal.

Sereñana y PARTAgÁs, Prudencio, 1882, La prostitución en Barcelona estudiada como enfermedad social y considerada como origen de otras enfermedades dinámicas, orgánicas y morales de la población barcelonesa. Barcelona, Imp. de los Sucesores de Ramírez y C.a.

VÁZQuez GARCíA, Francisco, 2015, «Alexandre Parent-Duchâtelet y la actualidad de las políticas reglamentistas en materia de prostitución». En Ana Remón Rodríguez, Rosa María Toribio Ruiz y Francisco Vázquez García, De la prostitution dans la ville de Paris... Par Alexandre Parent-Duchâtelet. Paris, 1857. (Colección Los Libros Olvidados. Biblioteca UCA, 2). Cádiz, Universidad: 5-27.

WALKowITZ, Judith, 1980, Prostitution and Victorian society: women, class, and the state. Cambridge, Cambridge University Press.

WALKOWITZ, Judith, 1990, «Vicio masculino y virtud feminista: el feminismo y la política sobre la prostitución en Gran Bretaña en el siglo XIX». En James Amelang y Mary Nash, Historia y género: las mujeres en la Europa moderna y contemporánea. Valencia, Alfons el Magnànim: 215-239.

WRIGHT, Maureen, 2011, Elizabeth Wolstenholme Elmy and the Victorian Feminist Movement. The biography of an insurgent woman. Manchester, Manchester University Press. 